\title{
DE COMO JUGAMOS A QUE LA RAZON ES VERDAD
}

Martha Pinto*

Queriendo darle voz a mis pensamientos que se hallaban en el cuarto de San Alejo y me estorbaban (uno nunca sabe por qué y para qué guarda tanto chéchere, pero tampoco se atreve a botarlos o regalarlos), quise, en un acto de valor, revisar y brillar algunos de ellos para sacarlos en la sala, es decir, en lo social, en el "súper yo"; para que aquellos que me visiten puedan a su antojo criticarlos.

Los objetos —pensamientos que decidí "sacar y brillar", tienen el siguiente orden de exposición (a propósito, los autores de esta "exposición" son Emanuel Kant y yo):

1. Concepto de autonomía.

2. Concepto de libertad.

3. Concepto de democracia.

4. Cómo se implementa la democracia en la educación.

Cuando Kant se plantea qué es la autonomía, parte del supuesto de que todo hombre posee una buena voluntad y entiende por ésta, aquella que es "capaz de rectificar y acomodar a un fin universal, el influjo de esa felicidad y con él el principio todo de la acción"93 . Y este supuesto se encuentra ya en la ilustración (véase Rosseau "El Contrato Social").

¿Cuál es el objeto de este supuesto? con este supuesto Kant, demuestra que en el obrar de todo individuo hay implícito un concepto de ley, de principio, por tanto de universidad, que le impide obrar como particular, así este individuo particular desconozca la ley y crea que su acción es exclusivamente particular. El desconocimiento de la ley significa para ese individuo particular que su obrar se torna en "deber".

Una de las hazañas kantianas (Kant tiene muchas) consiste en demostrar, cómo e se deber que aparentemente me obliga a actuar, me impone mandatos, imperativos, no se encuentra en el exterior, sino por el contrario ese "deber" nace de la interioridad de todo hombre que se piense como tal, es decir, en sentido de género y por ende como hombre inscrito en el universo.

En "sentido pedagógico" (véase incapacidad o desconocimiento) mostraré los pasos que Kant sigue para hacer esta afirmación.

Si aceptamos que tenemos una buena voluntad, ¿por qué no nos dejamos guiar por ella? Pues, ocurre que el hombre de la modernidad se halla escindido, desgarrado; por un lado están sus inclinaciones, apetencias, deseos y por el otro, la razón. Se pregunta Kant, ¿para qué tenemos la razón? "nos ha sido concedida la razón, como facultad práctica, como una facultad que debe tener influjo sobre la voluntad, resulta que el destino

\footnotetext{
* Filósofa de la Universidad Nacional, actualmente profesora del nuevo programa pre-escolar de la Universidad Pedagógica Nacional.

${ }^{93}$ Kant, Emanuel "Fundamentación a la metafísica de las costumbres” Ed. Porrua, pág. 21.
} 
verdadero de la razón es el de producir una voluntad buena, no en tal o cual respecto, como medio, sino buena en si misma" 94 . De lo cual se infiere que la felicidad no es la finalidad del hombre (planteamiento aristotélico), ya que si ésta fuera la finalidad del hombre, los sentidos cumplirían mejor dicha tarea. Por tanto, ¿cuál es el objeto de la razón? (encerrona kantiana, argumentación bien sólida sobre la razón y con razón). Sólo nos queda el camino de aceptar que tenemos la razón y que ésta tiene su finalidad. Cuando mi voluntad entiende la razón corno "deber", significa que subjetivamente mi querer no coincide con la necesidad objetiva de acción, es decir, objetivamente se me impone la necesidad de la acción pero, subjetivamente mi inclinación, mi deseo no es acorde con la necesidad objetiva de dicha acción. De esta forma se justifica la necesidad de los mandatos, de los imperativos.

Kant distingue dos tipos de imperativos: los hipotéticos y los categóricos. Son imperativos hipotéticos aquellos que mandan por la finalidad, es decir, "necesito esto, entonces debo hacer aquello". Mientras que el imperativo categórico manda por el principio y la forma misma, es decir, "no debo mentir aunque el hacerlo no me acarree ninguna vergüenza", manda no por la finalidad sino por el principio mismo.

De esta forma nos explica Kant por qué obedecemos la ley, que en este punto aparece como exterior a mí, obligándome, coaccionándome justamente porque mi acción está determinada por la necesidad, es decir mi acción es mandada sólo por imperativos hipotéticos; lo que significa que mi acción en el mundo depende de las circunstancias de éste, todavía el hombre está a merced del mundo. El mundo maneja al hombre. La propuesta de Kant, es que el hombre determine las leyes del mundo (Revolución Capernicana) es decir, que haga las leyes, lo cual significa acceder a la ciencia (dominio del hombre sobre la naturaleza) y lo mismo en el plano de lo moral. Es el hombre quien determinará las leyes de su obrar (imperativo categórico) y aquí nos preguntamos ¿qué es la autonomía? "Cuando una voluntad es capaz por sí misma de legislarse y hacer de sus máximas ley una legislación universal" ¿no es esto lo que consideramos autonomía? En otras palabras, ser autónomo significa interiorizar el imperativo categórico, significa plantearse como hombre en sentido universal, significa que soy responsable de mi acción, por tanto no voy a mandarme o a legislarme atentando contra mi propia persona, porque en mi está la humanidad ¿y no es ésto obrar con la razón? De donde autonomía y razón son una misma cosa.

Bueno y ¿en dónde está la libertad? siguiendo este planteamiento, la libertad como acción práctica, es decir en el mundo, consistiría en no obrar por imperativas hipotéticas o lo que es lo mismo, mi acción no puede estar mandada por la necesidad ni por los objetos de la necesidad.

Libertad en consecuencia es "la independencia de las causas que determinan el mundo sensible" sólo tiene posibilidad de darse en la esfera de la razón, por tanto en el mundo inteligible. Así cuando nos sentimos "obligados" es que nos encontramos en el mundo sensible, pero si nos pensamos como libres, nos incluimos en el mundo inteligible ¿por qué aparece nuevamente el fantasma metafísico de los dos mundos? La excusa que nos da Kant es que es un recurso que la razón se ve obligada a tomar si quiere explicarse al hombre como ser natural a la vez que como ser racional. Pero ¡ojo!, la astucia de la razón (véase

\footnotetext{
${ }_{94}^{94}$ Op. cit. pág. 23.

${ }^{95}$ Kant, Emanuel Op. cit. págs. 51-55.

${ }^{96}$ op. cit. pág. 59.
} 
Kant) no nos va a dejar dividido el mundo; de la manga nos saca el argumento de la unidad del mundo, pues como el mundo inteligible es el fundamento del sensible, el hombre tiene la posibilidad de pensarse como libre (y por tanto en el mundo inteligible), pero también cuando se siente sometido es que se encuentra en el mundo sensible.

En otras palabras, libertad consiste en elaborar y dictarse a sí mismo como hombre universal, las leyes.

Uno de los aspectos de la democracia consiste en que es el hombre, el ciudadano quien dieta las leyes que debe tener como características, que son universales, es decir, que sirven para cualquier hombre. Por tanto, la libertad que ofrece la democracia consiste en dietar leyes, acatarlas y cumplirlas. Pero ¿qué ocurre cuando se generan los cambios, los movimientos? frente a éstos la democracia les ofrece o mejor les impone como única alternativa el espacio de la legalidad, es decir, si hay que hacer cambios, estos tienen que darse necesariamente dentro del ámbito de la ley. Por consiguiente el ser que se considere autónomo o libre (lo cual es lo mismo) su espacio de acción está demarcado por los límites de la ley que él mismo ha hecho, por tanto está condenado a no romper sus límites porque ello significaría ser irracional, o lo que es lo mismo, pasar la frontera de la legalidad y encontrarse en la ilegalidad. La posibilidad de los movimientos dentro de la democracia se da en el plano de las reformas, son movimientos ordenados, son movimientos de la razón.

Y es en este momento en que la democracia se nos devela ya no como liberadora sino por el contrario como la preservadora de un pensamiento conservador y legitimador. Dejo abiertas estas preguntas:

\section{1. ¿Por qué el movimiento tiene que darse ordenado?}

\section{2. ¿Es la razón verdad?}

3. ¿Cómo se manifiesta la concepción democrática en las instituciones educativas y concretamente en el significado de educar?

Educar según esta concepción se da en los siguientes términos: sólo pueden educar aquellos que son mayores de edad, es decir, aquellos que han accedido a la razón, que han pasado por el proceso de hacerse hombres (universales), dictan la ley tanto para sí como para los que se hallan bajo su autoridad o sea los menores de edad (los estudiantes). Por consiguiente, su labor como educadores consistirá en que los menores de edad lleguen a obtener la razón. El fundamento de este sistema educativo parte del supuesto de que los menores de edad, los locos y los niños no tienen la razón (y todos lo hemos creído), por tanto, hay que suministrársela. ¿Cómo? Primero enseñando ciertos contenidos de tal manera que pasarán al curso siguiente si han memorizado, repetido y apropiado el discurso que tan bondadosa y sabiamente el maestro les ha determinado: ¿No les suena esto a soliloquio?, ¿a clase de lógica formal cuya base es la lógica del sí y la lógica del no? ¿Verdad que sí?

En el estudiante la situación se expresa de esta forma: en primer lugar, no sabe para qué lo educan y por tanto acepta la condición, pero cuando ha cumplido su ciclo corno estudiante se aproxima a la mayoría de edad está también encauzado en la razón que ha ido adquiriendo con tanto dolor y esfuerzo (acuérdate de los exámenes, las previas, las rayadas, los ceros, las angustias, etc.), que ve corno peligroso e inseguro su transistor por la senda del conocimiento sin la guía, ni la aprobación o el rechazo del maestro. Además 
es más cómodo que alguien me diga sí sé o no; así no asumo ninguna responsabilidad frente a mi saber. Es el maestro quien sabe si yo sé.

Las "virtudes" que garantizan este tipo de educación en un profesional son: la de un excelente repetidor de las leyes, de ideas, además de un defensor inmediato de dicho sistema, pues le está agradecido porque le posibilitó hacerse profesional.

Los que lleguen al Magíster o Doctorado "superarán" a los profesionales a secas en el sentido de que ellos (los doctores) serán los encargados de darle paso al movimiento, pero ¡cuidado! ¡no al desorden! por el contrario al movimiento ordenado, es decir, la reforma. $Y$ de esta forma legalizar los cambios para darle espacio a estos movimientos dentro del ámbito de la ley, de tal manera que no se nos conviertan en irracionales, es decir, fuera de la razón y, por consiguiente, que atenten contra ella: la razón-ley.

Tengo nuevamente dos preguntas abiertas:

1. ¿Será posible educar bajo otro principio diferente a éste?

2. Educando de esta manera, ¿cómo podremos hacer el futuro? 